\title{
Reife Elektroautos
}

\section{Liebe Leserin, lieber Leser,}

die Elektromobilität erntet weltweit die ersten Früchte ihrer Arbeit. Zahlreiche Modelle mit einem „e“ im Namen sind mittlerweile erhältlich, seien sie von einheimischen oder ausländischen OEMs. Nun muss nur noch der inländische Markt dauerhaft anspringen.

\section{Allen Unkenrufen zum Trotz setzen} unsere Politiker und Automobilhersteller auf diese kraftvolle und emissionsarme Fortbewegungsart. In eine umweltfreundliche Mobilität der Zukunft führt kein anderer als dieser Weg. Auch wenn es noch 2013 im Koalitionsvertrag hieß, bei der Unterstützung des Markthochlaufs der Elektromobilität wird ,auf nutzerorientierte Anreize statt eine Kaufprämie“ gesetzt, machte Angela Merkel letztere nun in Deutschland dann doch zur Wirklichkeit: Für ein E-Auto werden dem Käufer 4000 Euro und für einen Plug-inHybrid 3000 Euro Zuschuss gezahlt. Ob man die Prämie nun mag oder nicht: Sie kommt arg spät, wird ihren Effekt aber zeigen, denn sie wirkt sowohl medienwirksam als auch monetär.

Der Erfolg wird sich messen lassen: Zählten die Deutschen nur 0,7 \% Elektroauto-Anteil an den zugelassenen Neuwagen in 2015, verzeichneten die Niederlande $10 \%$ und Norwegen bereits $23 \%$, auch weil dort die Infrastruktur schon repräsentativ aufgebaut wurde. Dank der Prämie griffen bis 14. Juli 936 und bis 29. Juli bereits 1523 deutsche Käufer zu. Wenn die Förderung der deutschen Ladeinfrastruktur umgesetzt ist, dürfte die Wachstumsrate noch deutlicher ausfallen. Attraktive und alltagstaugliche Elektround Plug-in-Hybrid-Modelle gibt es ja mittlerweile reichlich. Neben Audi A3 e-tron, BMW i3 und VW eGolf sowie den seit rund vier Jahren meistverkauften Fahrzeugen wie Renault Zoe und Nissan Leaf bieten bald Hyundai die Plug-in-Hybrid-Limousine Ioniq und Kia den Niro als SUV-Pendant an. Im Juni erklärte Henning Kagermann als Vorsitzender der Nationalen Plattform Elektromobilität (NPE) in Berlin: „Die Frage ist nicht, ob die Elektromobilität kommt, sondern wie gut wir in Deutschland darauf vorbereitet sein werden." Die NPE-Roadmaps zu Forschung und Entwicklung müssten weiter konsequent abgearbeitet werden.

Dem möchte man entgegnen: Bei allen F\&E-Ergebnissen, die in den letzten fünf Jahren in den sogenannten Schaufenstern erarbeitet wurden, soll jetzt an Incentivierung mit Prämien, Marketing und Handel für einen nachhaltigen Markteintritt gedacht werden - und damit an die Umsetzung der Forschungsergebnisse in die Realität. In diesem Zusammenhang fordert auch Franz Loogen, Geschäftsführer E-Mobil BW, „weniger Bedenkenträger und kurzfristiges Gewinnstreben, sondern mehr Macher und kaufmännischen Mut“. Dann hängt das Obst nicht nur reif am Baum, sondern wird auch gegessen. Für die Ernte in den Folgejahren sorgen technische Weiterentwicklungen, wie sie im Titelthema dieses Hefts zu Batterie- und Brennstoffzellentechnik zu lesen sind.

Herzliche Grüße,

Ihr

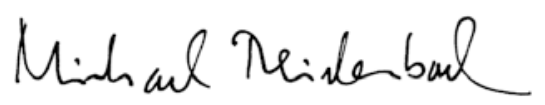

Dipl.-Ing. Michael Reichenbach Stellvertretender Chefredakteur

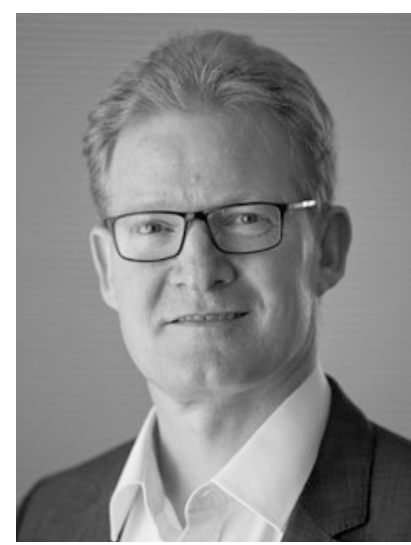

DRAXLMAIER

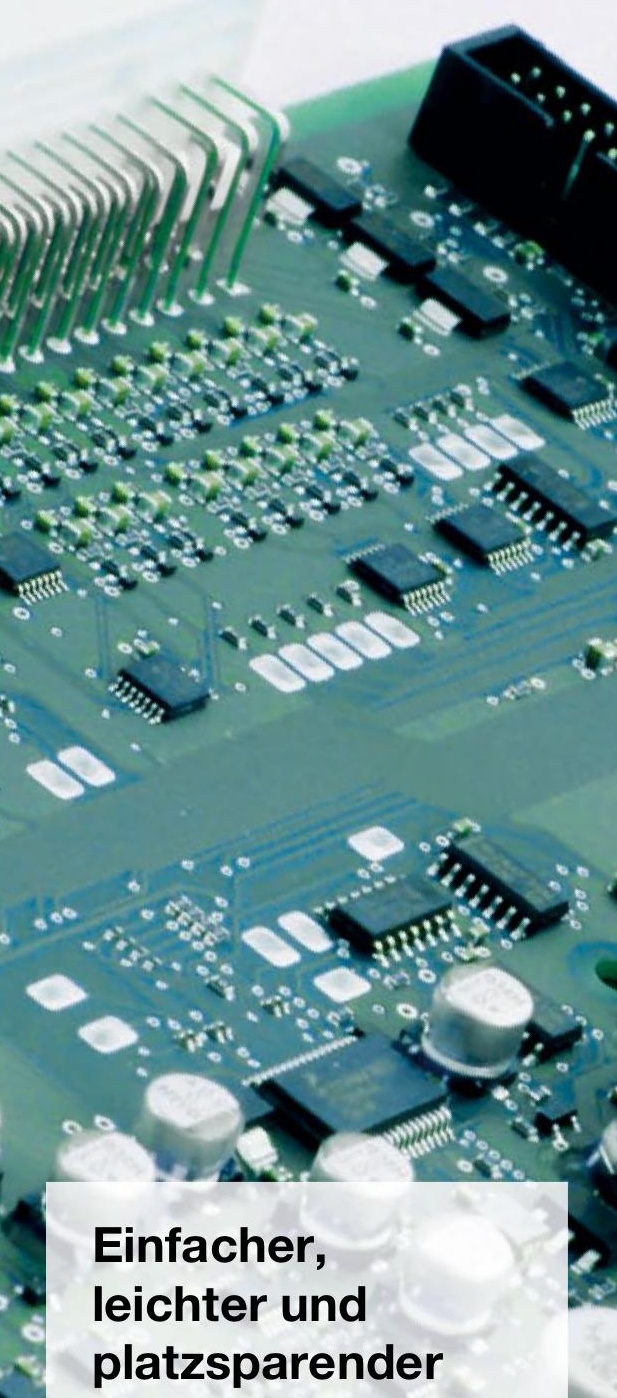

Sie suchen nach Elektrikund Elektronik-Lösungen zur Reduktion von Komplexität, Kosten, Gewicht und Bauraum?

Profitieren Sie vom umfassenden Know-how des Systempartners. In den Bereichen Systemarchitektur, Elektrik, Elektronik, Software, Mechatronik, Integration, Test und Absicherung bietet die DRÄXLMAIER Group maßgeschneiderte Produkte zur Erfüllung höchster Kundenanforderungen. Das Speichern, Wandeln, Verteilen und Absichern von Energie ist dabei unsere Kernkompetenz.

www.draexImaier.com / elektronik 